\title{
Mesoscale Horizontal Kinetic Energy Spectra of a Tropical Cyclone
}

\author{
YuAN WANG, LIFENG ZHANG, AND JUn PENG \\ College of Meteorology and Oceanography, National University of Defense Technology, Nanjing, China \\ SAISAI LIU \\ College of Meteorology and Oceanography, National University of Defense Technology, Nanjing, and Unit 31010, \\ People's Liberation Army, Beijing, China
}

(Manuscript received 22 December 2017, in final form 8 July 2018)

\begin{abstract}
A high-resolution cloud-permitting simulation with the Weather Research and Forecasting (WRF) Model is performed to investigate the mesoscale horizontal kinetic energy (HKE) spectra of a tropical cyclone (TC). The spectrum displays an arc-like shape in the troposphere and a quasi-linear shape in the lower stratosphere for wavelengths below $500 \mathrm{~km}$ during the mature period of the TC, while they both develop a quasi $-5 / 3$ slope. The total HKE spectrum is dominated by its rotational component in the troposphere but by its divergent component in the lower stratosphere. Further spectral HKE budget diagnosis reveals a generally downscale cascade of HKE, although a local upscale cascade gradually forms in the lower stratosphere. However, the mesoscale energy spectrum is not only governed by the energy cascade, but is evidently influenced also by other physical processes, among which the buoyancy effect converts available potential energy (APE) to HKE in the mid- and upper troposphere and converts HKE to APE in the lower stratosphere, the vertically propagating inertia-gravity waves transport the HKE from the upper troposphere to lower and higher layers, and the vertical transportation of convection always transports HKE upward.
\end{abstract}

\section{Introduction}

The energy spectrum is a fundamental issue in geophysical fluids and turbulence (Bierdel et al. 2012). Observational studies based primarily on data obtained from commercial aircraft flights have shown that the horizontal kinetic energy (HKE) spectra in the upper troposphere and lower stratosphere exhibit a robust spectral shape that follows a power-law dependence with an approximate -3 slope at the synoptic scale and transits to an approximate $-5 / 3$ slope in the mesoscale range corresponding to wavelengths below $\sim 500 \mathrm{~km}$ (e.g., Nastrom and Gage 1985). The synoptic-scale -3 power law is known to be well explained by the theory of geostrophic turbulence (Charney 1971); however, the mechanism responsible for the mesoscale $-5 / 3$ power law is still controversial.

In early studies, two completely different mechanisms were proposed to explain the mesoscale $-5 / 3$ spectral slope. One is the forward (downscale) energy cascade of weakly nonlinear inertia-gravity waves (e.g., Dewan 1979); the

Corresponding author: Lifeng Zhang, zhanglif_qxxy@sina.cn other is the inverse (upscale) energy cascade of strongly nonlinear quasi-two-dimensional (2D) stratified turbulence (e.g., Gage 1979). However, numerical simulations of stratified turbulence showed that strong stratification alone favors a downscale cascade (e.g., Riley and deBruynKops 2003), and observations also revealed downscale energy fluxes in the real atmosphere (e.g., Lindborg and Cho 2001). These results cast doubt on the second proposed mechanism and drove the exploration in recent years of the possibility of downscale energy cascade in mesoscale atmospheric turbulence. Overall, several alternative hypotheses have been proposed, including double cascades in quasigeostrophic turbulence (e.g., Tung and Orlando 2003), forward cascade in surface quasigeostrophic turbulence (e.g., Tulloch and Smith 2006), and anisotropic three-dimensional (3D) turbulence with strong stratification (e.g., Lindborg 2006).

Summarized in Waite and Snyder (2013), the observed mesoscale energy spectrum has been reproduced in a variety of numerical simulations of the atmosphere, using both global (e.g., Koshyk and Hamilton 2001) and regional (e.g., Skamarock 2004) models. Assuming model dynamics 
to be reliable, high-resolution output from numerical simulations can be used to conduct accurate spectral energy budget diagnosis, and such comprehensive models can therefore provide a convenient framework for examining the formation mechanisms of the mesoscale energy spectrum (e.g., Koshyk and Hamilton 2001). Recently, several studies have performed idealized simulations on specific systems, such as baroclinic waves (Waite and Snyder 2009, 2013; Peng et al. 2015a,b), mei-yu fronts (Peng et al. 2014), and convective clouds (Sun et al. 2017), to provide detailed information on the related mesoscale energy spectra and their budgets.

Understanding the energy spectrum and its formation is not only an interest of theoretical study but also has practical implications. For example, it benefits the study of atmospheric predictability (e.g., Lorenz 1969; Rotunno and Snyder 2008; Sun and Zhang 2016). Given the spectrum, conclusions can be drawn as to how quickly smallscale errors will contaminate large scales (Vonich and Hakim 2018). As early as 1969, Lorenz demonstrated that a flow governed by a $k^{-p}$ power law has limited predictability when $p<3$, but it has unlimited predictability when $p \geq 3$. Further, the formation mechanisms of energy spectrum have the potential of explaining the predictability (e.g., Sun and Zhang 2016), which is still being explored.

As one of the most vigorous moist convective systems, a tropical cyclone (TC) possesses complex multiscale interaction processes (e.g., Ritchie and Holland 1997; Rogers et al. 2015) that make it difficult to obtain a complete understanding of its dynamics, thus limiting the forecast of TC intensity (Marks and Shay 1998). The restrictions of traditional synoptics, dynamics, and energetics methods mean that our knowledge on these processes has remained limited. The method of energy spectrum analysis, in contrast, has certain advantages in this area of research. From an energetics perspective, the change of TC intensity is the direct reflection of variations in the systematic energy. The evolution of a TC is essentially accompanied by the input, output, cascade, conversion, and vertical transportation of energy through various physical processes (e.g., moist convection, radiation, and dissipation) that occur at different scales. These components can be systematically analyzed in spectral space through energy spectrum analysis and spectral energy budget diagnosis, thus providing a better understanding of the internal dynamics and energetics of TCs and the atmospheric mesoscale energy spectrum.

In the study presented here, the issues discussed above are preliminarily explored by examining the mesoscale HKE spectra of an idealized TC simulated by the Weather Research and Forecasting (WRF) Model. The available potential energy (APE) spectra of the TC is investigated in Y. Wang et al. (2018, unpublished manuscript). The remainder of the paper is organized as follows. A brief description of the model configuration and an overview of the simulation are presented in section 2. Section 3 describes the evolutions and characteristics of the simulated mesoscale HKE spectra. A detailed diagnosis of the spectral HKE budget is presented in section 4, followed by a summary and a discussion in section 5 .

\section{Model configuration and overview of the simulated TC}

\section{a. Experimental setup}

The Advanced Research version of WRF (ARW; Skamarock et al. 2008), version 3.6, is employed to perform a simulation on the double periodic $f$ plane, and the domain size is $2000 \mathrm{~km} \times 2000 \mathrm{~km}$, with a horizontal grid spacing of $5 \mathrm{~km}$. There are 51 vertical layers and the model top is set to $25 \mathrm{~km}$. No nested domain is adopted.

The model uses the Yonsei University (YSU) boundary layer scheme (Hong et al. 2006) with the surface layer scheme of Dudhia et al. (2008) and the WRF singlemoment six-class microphysics scheme (WSM6; Hong and Lim 2006), but no convective parameterization or radiation scheme. Turbulence mixing in the model is parameterized using the horizontal Smagorinsky firstorder closure scheme. Rayleigh damping is applied to the vertical velocity in the upper $5 \mathrm{~km}$ of the model domain to prevent the artificial reflection of gravity waves from the model top (Klemp et al. 2008).

An initial axisymmetric vortex in hydrostatic and gradient wind balance is centered in the model domain, with a maximum tangential surface wind speed of $15 \mathrm{~m} \mathrm{~s}^{-1}$ at a radius of $135 \mathrm{~km}$. The background atmosphere is motionless, and the basic-state potential temperature and humidity are based on the Jordan (1958) mean hurricane season sounding. The sea surface temperature and Coriolis parameter $f$ are set to $28^{\circ} \mathrm{C}$ and $5.0 \times 10^{-5} \mathrm{~s}^{-1}$, respectively. The simulation is integrated for $144 \mathrm{~h}$ with field output every hour.

\section{b. Overview of the simulation}

Figure 1a shows the time series of $10-\mathrm{m}$ maximum wind speed and minimum sea level pressure of the TC during the simulation. After an initial adjustment, the 10-m maximum wind speed begins to increase slowly from $\sim 30 \mathrm{~h}$, and the minimum sea level pressure decreases correspondingly. The intensification of the TC becomes increasingly evident from $\sim 54 \mathrm{~h}$, and the maximum intensity occurs at $\sim 84 \mathrm{~h}$, with a $10-\mathrm{m}$ maximum wind speed of $\sim 60 \mathrm{~m} \mathrm{~s}^{-1}$ and a minimum sea level pressure of $\sim 940 \mathrm{hPa}$. The TC then reaches its mature phase, with the intensity remaining quasi steady. 

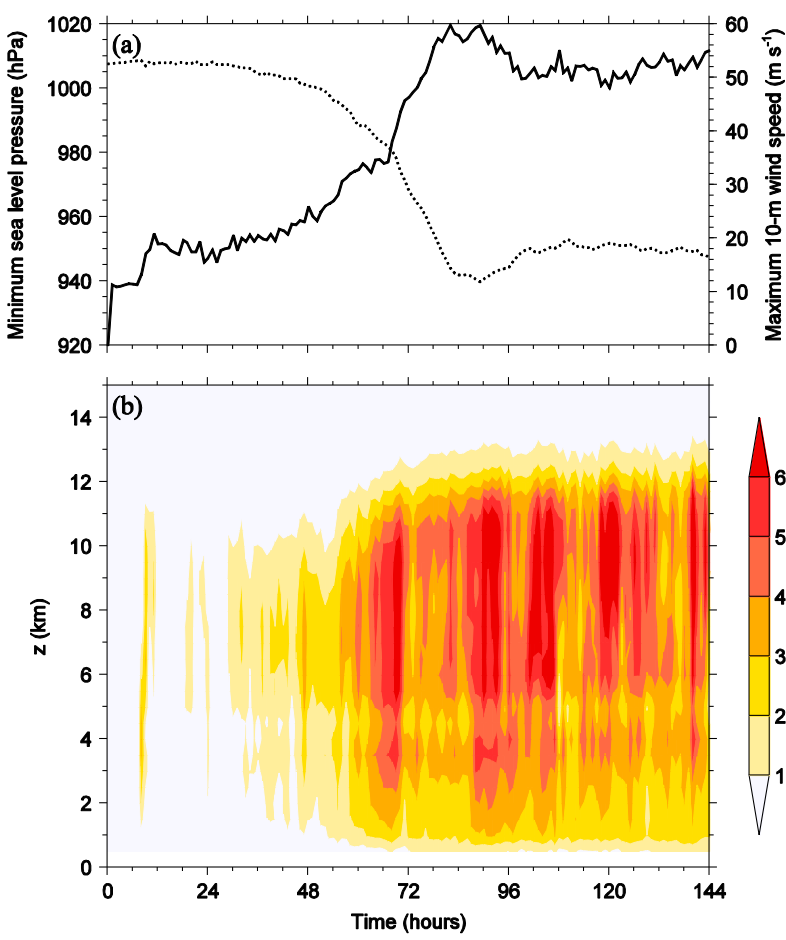

FIG. 1. Time evolutions of the (a) minimum sea level pressure (dotted line; $\mathrm{hPa}$ ) and maximum 10-m wind speed (solid line; $\mathrm{m} \mathrm{s}^{-1}$ ), and (b) diabatic heating rate averaged over the main convective region (shaded; $\mathrm{K} \mathrm{h}^{-1}$ ).

The time evolution of the diabatic heating rate averaged over the main convective region (i.e., $900<x<1100 \mathrm{~km}$, $900<y<1100 \mathrm{~km}$ ) is shown in Fig. 1b. As the TC intensifies, the heating increases slowly from $\sim 30 \mathrm{~h}$ and strengthens further at $\sim 54 \mathrm{~h}$. The relatively strong heating persists for the remainder of the simulation, which penetrates the whole troposphere and is confined to $13 \mathrm{~km}$, with two maximum centers at $\sim 3$ and $\sim 8 \mathrm{~km}$, respectively. According to the vertical distribution of diabatic heating and the basic-state Brunt-Väisälä frequency (not shown), we refer to $z=0-5,6-12$, and $16-18 \mathrm{~km}$ as the lower to midtroposphere, upper troposphere, and lower stratosphere, respectively.

At $70 \mathrm{~h}$ when the TC is intensifying, a distinct warm core is located at a height of $\sim 8 \mathrm{~km}$ (Fig. $2 \mathrm{a}$ ). The maximum tangential wind, which exceeds $45 \mathrm{~m} \mathrm{~s}^{-1}$, is located near the ground with a radius of $\sim 40 \mathrm{~km}$. The radial wind and vertical velocity exhibit a typical secondary circulation structure of TC: radial wind inflows in the lower level and outflows in the upper level, with the upward motion slanting away from the TC center with height (Fig. 2b).

\section{Horizontal kinetic energy spectra}

The HKE spectra are computed here by performing 2D discrete Fourier transform (DFT) of the horizontal
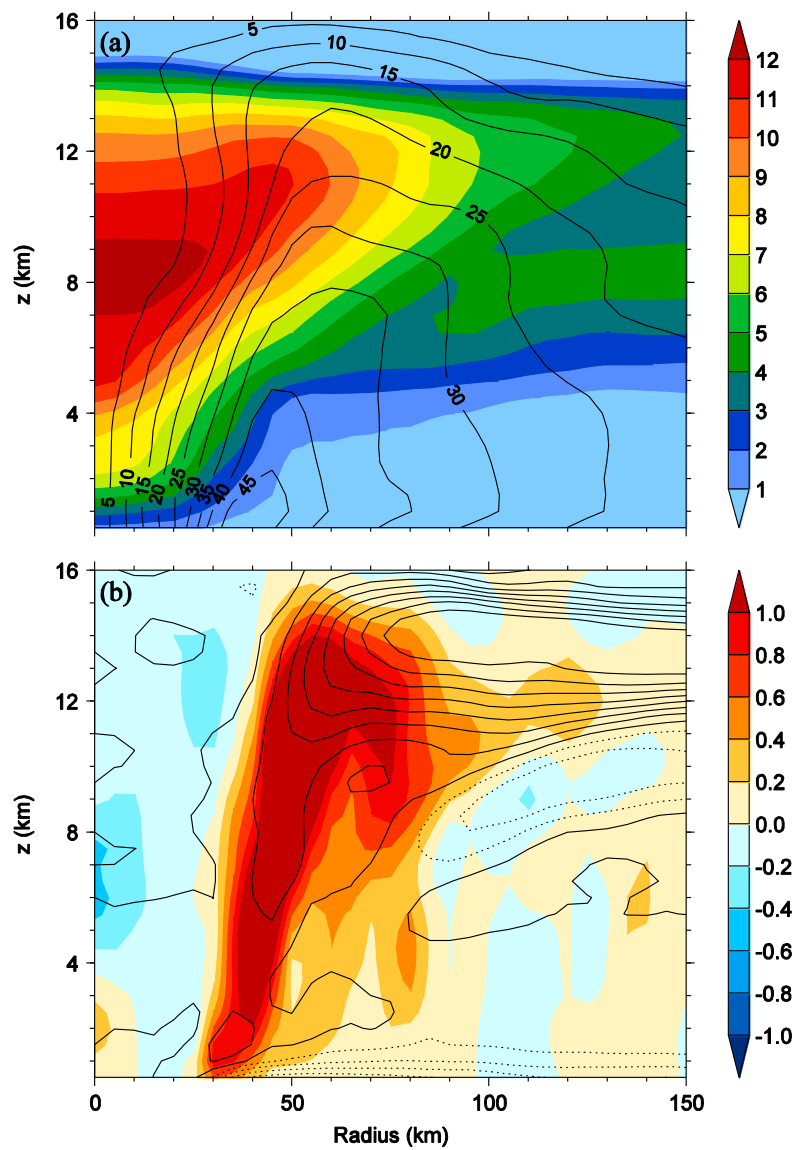

FIG. 2. Height-radius cross sections of azimuthal-mean (a) potential temperature change since the initial time (shaded; K) and tangential velocity (contours; $\mathrm{m} \mathrm{s}^{-1}$ ), and (b) vertical velocity (shaded; $\mathrm{m} \mathrm{s}^{-1}$ ) and radial velocity (contours every $2 \mathrm{~m} \mathrm{~s}^{-1}$ with negative contours dotted) at $70 \mathrm{~h}$.

velocity $\mathbf{u}=(u, v)$ over the entire simulation domain at each height level. Let $\hat{\varphi}(\mathbf{k})$ be the Fourier coefficients of field $\varphi$, where $\mathbf{k}=\left(k_{x}, k_{y}\right)$ is the horizontal wave vector. Dependence of spectral quantities on $z$ and $t$ is suppressed for clarity. Subsequently, the HKE spectrum per unit volume at a given time and vertical level is

$$
E_{h}(\mathbf{k})=\frac{1}{2} \bar{\rho}_{d}\left[\hat{u}(\mathbf{k}) \hat{u}^{*}(\mathbf{k})+\hat{v}(\mathbf{k}) \hat{v}^{*}(\mathbf{k})\right],
$$

where $\bar{\rho}_{d}$ denotes the density of dry reference state, and the asterisk denotes the complex conjugate. We calculate the HKE spectrum per unit volume rather than per unit mass in order to facilitate the comparison of spectra at different heights. The HKE spectrum can be further decomposed into horizontally rotational and divergent contributions $\left[E_{R}(\mathbf{k})\right.$ and $E_{D}(\mathbf{k})$, respectively; e.g., Waite and Snyder 2009], given by 


$$
\begin{aligned}
& E_{R}(\mathbf{k})=\frac{1}{2} \bar{\rho}_{d} \frac{\hat{\zeta}(\mathbf{k}) \hat{\zeta} *(\mathbf{k})}{|\mathbf{k}|^{2}} \text { and } \\
& E_{D}(\mathbf{k})=\frac{1}{2} \bar{\rho}_{d} \frac{\hat{\delta}(\mathbf{k}) \hat{\delta} *(\mathbf{k})}{|\mathbf{k}|^{2}}
\end{aligned}
$$

where $\zeta=\partial v / \partial x-\partial u / \partial y$ and $\delta=\partial u / \partial x+\partial v / \partial y$.

The total horizontal wavenumber is defined as $k_{h}=$ $|\mathbf{k}|=\sqrt{k_{x}^{2}+k_{y}^{2}}$, so the one-dimensional (1D) HKE spectrum as a function of $k_{h}$ is constructed by angular averaging over wavenumber bands $k_{h}-\Delta k / 2 \leq|\mathbf{k}|<k_{h}+\Delta k / 2$ on the $k_{x}-k_{y}$ plane (e.g., Waite and Bartello 2004), with $k_{h}$ being the central radius of the bands such that

$$
E_{h}\left(k_{h}\right)=\sum_{k_{h}-\Delta k / 2 \leq|\mathbf{k}|<k_{h}+\Delta k / 2} E_{h}(\mathbf{k}) / \Delta k,
$$

where $\Delta k=2 \pi /(\Delta \times N)$ and $N=\min \left(N_{i}, N_{j}\right)$. The terms $N_{i}$ and $N_{j}$ are the number of zonal and meridional grid points, respectively; and $\Delta$ is the horizontal grid spacing. The $1 \mathrm{D}$ rotational and divergent kinetic energy spectra [ $E_{R}\left(k_{h}\right)$ and $E_{D}\left(k_{h}\right)$, respectively] are constructed analogously to $E_{h}\left(k_{h}\right)$.

\section{a. Time evolutions of the HKE spectra}

Figures 3-5 show the time evolutions of the HKE spectra averaged over the lower to midtroposphere, upper troposphere, and lower stratosphere, respectively. Note that the effective resolution for the WRF Model is $\sim 7$ times the horizontal grid spacing (i.e., $\sim 35 \mathrm{~km}$ here) because of numerical diffusion (Skamarock 2004); therefore, we focus on the well-resolved horizontal wavelengths $\lambda_{h}$ above $40 \mathrm{~km}$ in the present paper.

In the lower to midtroposphere (Fig. 3), the HKE spectrum falls off rapidly with wavenumber initially as a result of the absence of fine structure in the initial fields. It is noteworthy that leaving the plateau at the smallest wavenumbers, the initial spectrum drops sharply for $k_{h}>2 \pi / 5 \times 10^{-5} \mathrm{rad} \mathrm{m}^{-1}\left(\lambda_{h}<500 \mathrm{~km}\right)$, which is also observed in the upper troposphere (Fig. 4) and lower stratosphere (Fig. 5). As the initial fields merely contain the preset vortex with quiet background flow, the spectrum entirely reflects the feature of the vortex, and a wavelength of $500 \mathrm{~km}$ actually corresponds to the scale of the cyclone. From 6 to $12 \mathrm{~h}$, the spectrum experiences a significant adjustment and rises for $k_{h}>\pi \times 10^{-5} \mathrm{rad} \mathrm{m}^{-1}$ $\left(\lambda_{h}<200 \mathrm{~km}\right)$, which can be treated as spinup in the early integration. After $30 \mathrm{~h}$, as the TC slowly intensifies, the HKE spectrum begins to grow over the central mesoscale, most remarkably at $k_{h} \approx 6 \pi \times 10^{-6} \mathrm{rad} \mathrm{m}^{-1}$ $\left(\lambda_{h} \approx 333 \mathrm{~km}\right)$. The growth of energy continuously extends to smaller scales from $\sim 54 \mathrm{~h}$ eventually down to $k_{h} \approx \pi / 2 \times 10^{-4} \mathrm{rad} \mathrm{m}^{-1}\left(\lambda_{h} \approx 40 \mathrm{~km}\right)$, below which the numerical diffusion dominates the simulation. The whole HKE spectrum reaches saturation at $\sim 84 \mathrm{~h}$, after which the spectral shape remains constant.

The HKE spectral evolution in the upper troposphere (Fig. 4) resembles that in the lower to midtroposphere. The spectrum sequentially experiences an initial adjustment, growth over the central mesoscale, growth extending to smaller scales, and saturation periods. However, the spectral development in the lower stratosphere (Fig. 5) differs slightly from those in the troposphere. For $t=30$ $54 \mathrm{~h}$, when the spectrum in the troposphere grows over the central mesoscale, the lower-stratospheric spectrum exhibits growth only over the large end of the mesoscale for $k_{h}<\pi / 4 \times 10^{-5} \mathrm{rad} \mathrm{m}^{-1}\left(\lambda_{h}>800 \mathrm{~km}\right)$. It is seen to increase and then extend down to smaller scales while confined to $k_{h}<2 \pi \times 10^{-5} \mathrm{rad} \mathrm{m}^{-1}\left(\lambda_{h}>100 \mathrm{~km}\right)$ before spectral saturation occurs.

Despite certain differences, the HKE spectral developments in the lower to midtroposphere, upper troposphere, and lower stratosphere occur almost simultaneously, which is expected-as a deep system, the TC should have coupled changes at different heights during its evolution. Overall, the evolution of the TC can be divided into three periods: (i) the slow intensification (SI) period $(t=31-54 \mathrm{~h})$, which is characterized by slow intensification of the TC and evident growth of the tropospheric and stratospheric HKE spectra over the central and large end of the mesoscale, respectively; (ii) the rapid intensification (RI) period $(t=55-84 \mathrm{~h})$, which is characterized by rapid intensification of the TC and growth of the HKE spectra extending to smaller scales; and (iii) the mature period $(t=85-120 \mathrm{~h})$, which is characterized by a steady intensity of the TC and saturation of the HKE spectra.

\section{b. HKE spectral characteristics during the mature period}

The time-averaged HKE spectra in the mature period-during which the spectra achieve saturation and are approximately stationary-are shown in Fig. 6. As the density decreases with height, the amplitude of the spectrum decreases from the lower to midtroposphere to the lower stratosphere.

In the lower to middle and upper troposphere, the mature HKE spectra fill out over the central mesoscale and exhibit an arc-like shape for $40<\lambda_{h}<500 \mathrm{~km}$. Note that the spectra have a distinct peak at $\lambda_{h}=500 \mathrm{~km}$ (i.e., the cyclone scale), which will be further discussed in section 4. In the lower stratosphere, the spectrum shows no significant expansion for any of the resolved wavelengths and develops a quasi-linear shape throughout the whole mesoscale. In general, the mesoscale HKE spectra at different heights all reproduce the quasi $-5 / 3$ slope for 

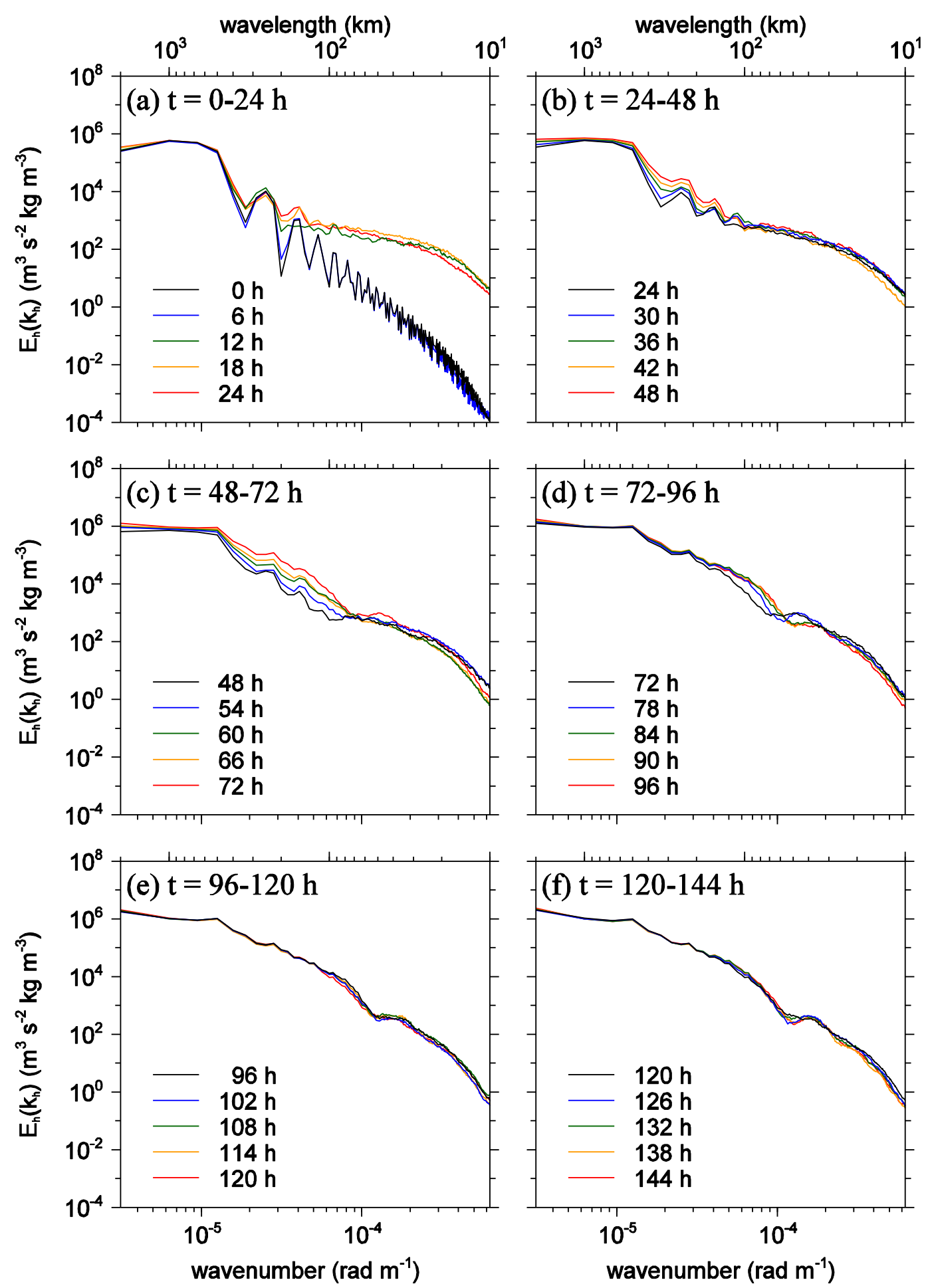

FIG. 3. Horizontal wavenumber spectra of HKE for $t=$ (a) 0-24, (b) 24-48, (c) 48-72, (d) 72-96, (e) 96-120, and (f) 120-144 h, averaged vertically over the lower to midtroposphere. Spectra are plotted every $6 \mathrm{~h}$.

$\lambda_{h}<500 \mathrm{~km}$ in a real atmosphere to some extent. The lower-stratospheric spectrum approaches the $-5 / 3$ slope better over the whole scale range for $40<\lambda_{h}<500 \mathrm{~km}$. However, because of the arc-like shape, the spectrum in the troposphere steepens for $\lambda_{h}<100 \mathrm{~km}$. This steepening of the energy spectrum has also been revealed by recent observational research on hurricane kinetic energy spectra (Vonich and Hakim 2018), which supports 

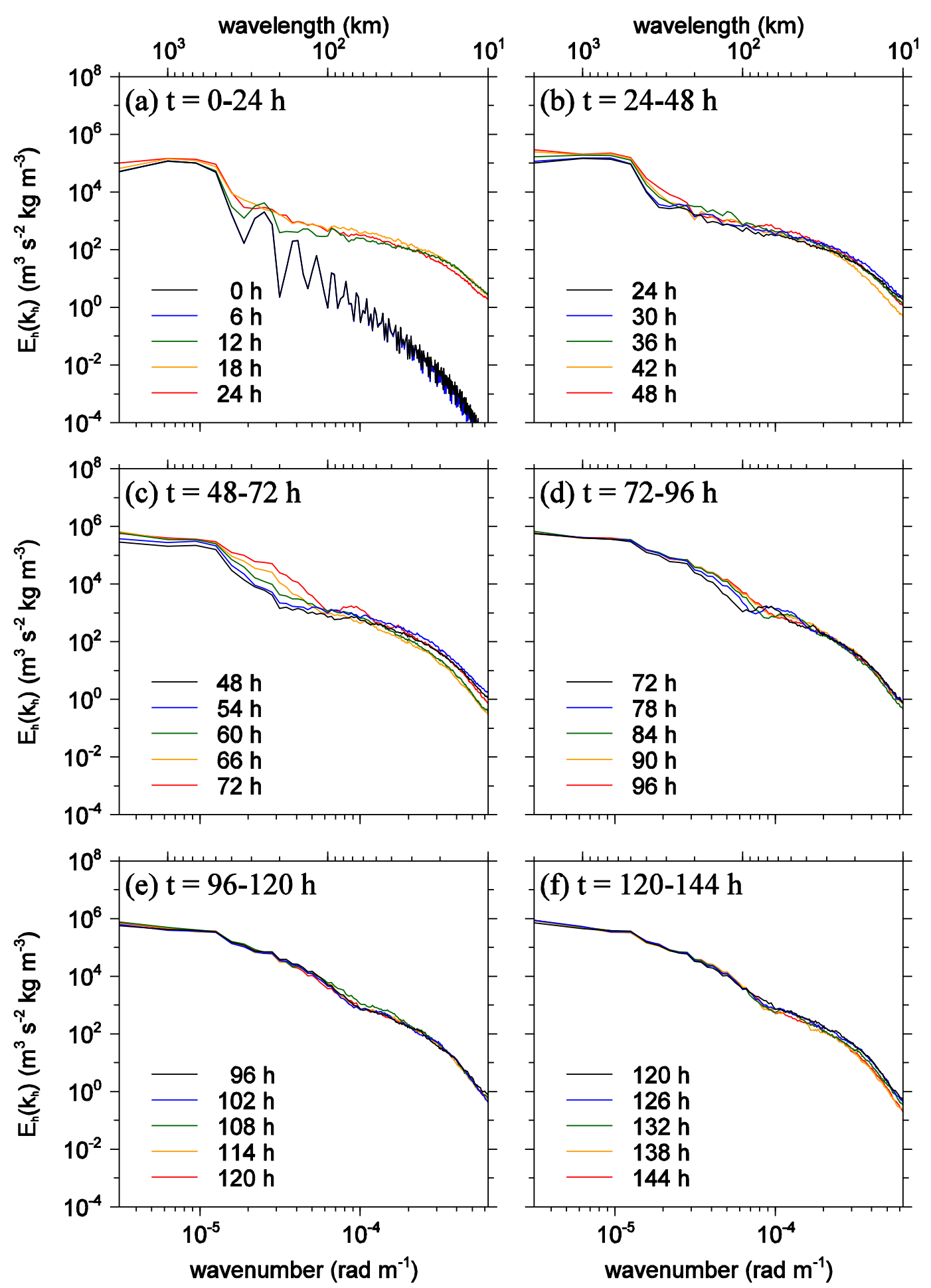

FIG. 4. As in Fig. 3, but averaged vertically over the upper troposphere.

our finding and suggests that the result here is a realistic and robust feature for TCs.

Figure 7 details the rotational and divergent kinetic energy spectra averaged over the mature period. Regardless of the atmospheric level, the divergent kinetic energy (DKE) spectra are relatively linear throughout the whole mesoscale for $\lambda_{h}>40 \mathrm{~km}$, with a slope slightly shallower than $-5 / 3$. 

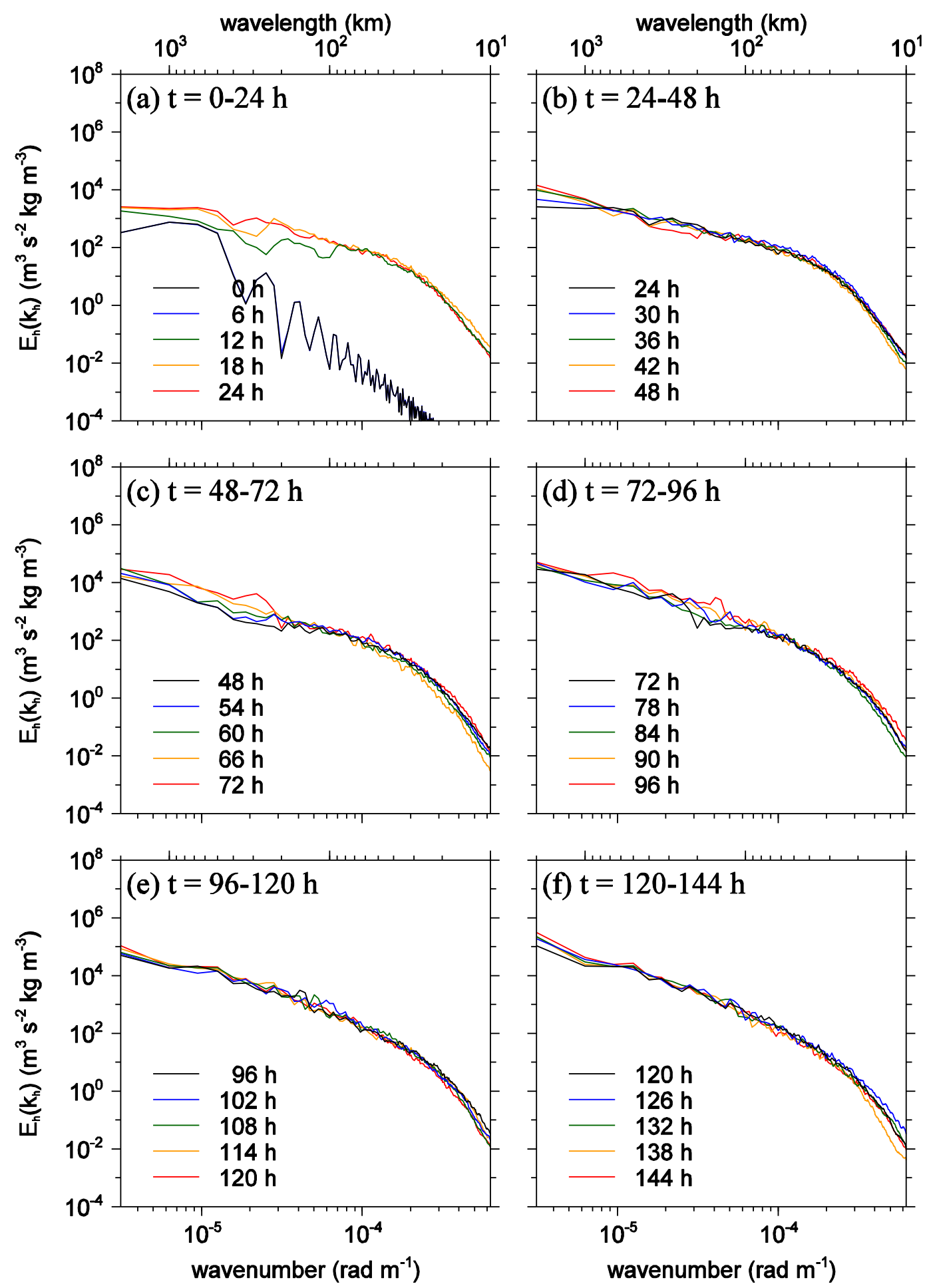

FIG. 5. As in Fig. 3, but averaged vertically over the lower stratosphere.

In the lower to midtroposphere (Fig. 7a), the rotational kinetic energy (RKE) spectrum exhibits an arclike shape similar to the total HKE spectrum and dominates the DKE spectrum for $\lambda_{h}>80 \mathrm{~km}$. Over this scale range, $\mathrm{RKE}$ is at least an order of magnitude larger than DKE, with the maximum ratio of RKE to DKE approaching 102. At smaller scales, the magnitudes of RKE and DKE are comparable. The domination of 


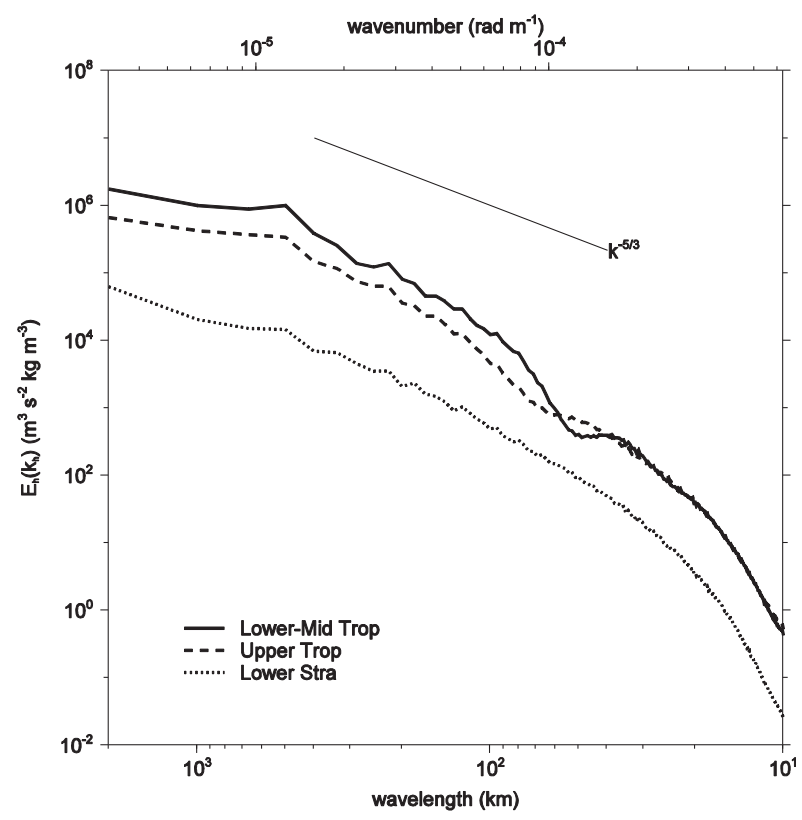

FIG. 6. Horizontal wavenumber spectra of HKE averaged over the mature period, and vertically over the lower to midtroposphere (solid line), upper troposphere (dashed line), and lower stratosphere (dotted line). The reference line corresponds to the $-5 / 3$ slope.

RKE in the total HKE spectrum indicates the strong vorticity of the TC. In the upper troposphere (Fig. 7b), the lower limit of the domination wavelengths of RKE shifts up to $\sim 200 \mathrm{~km}$, and the ratio between RKE and DKE overall is less than that in the lower to midtroposphere, with the maximum ratio reducing to $\sim 34$.

Regarding the lower stratosphere (Fig. 7c), the RKE spectrum is quasi linear over all well-resolved scales with no prominent expansion, and it no longer dominates the DKE spectrum at any scale. For $\lambda_{h}>150 \mathrm{~km}$, the RKE spectrum is comparable to that for DKE. The amplitude of the DKE is an order of magnitude larger than that of the RKE at smaller scales, owing to the fact that gravity waves are the primary signals at this height (e.g., Kuester et al. 2008; Kim and Chun 2010). Together, the steeper RKE spectrum and the shallower DKE spectrum yield the quasi $-5 / 3$ slope of the mesoscale HKE spectrum in the lower stratosphere.

\section{Spectral HKE budget}

The HKE spectral characteristics of the TC are detailed in section 3. Here we gain insight into the dynamics of HKE spectra by examining the spectral HKE budget to investigate the mechanisms responsible for the growth and maintenance of the HKE. Following Peng et al. (2015a), a new formulation of the spectral
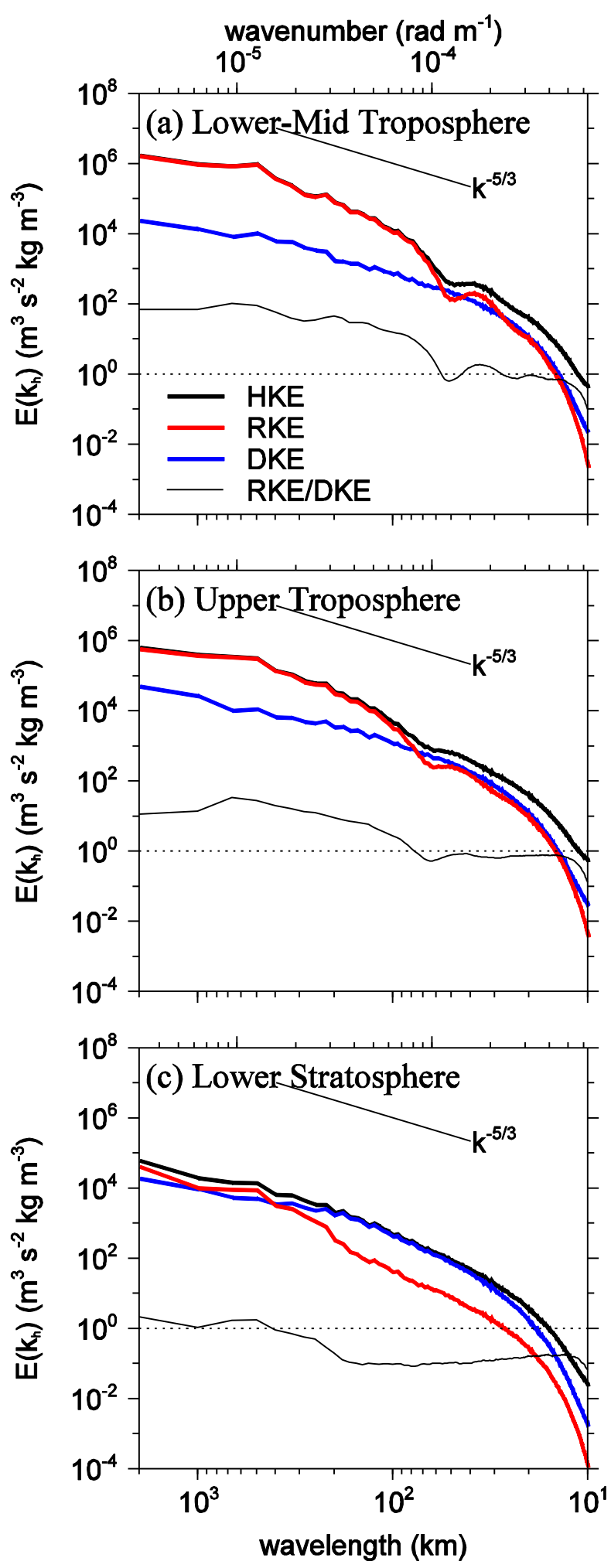

FIG. 7. Horizontal wavenumber spectra of HKE (thick black line), RKE (thick red line), and DKE (thick blue line) averaged over the mature period, and vertically over the (a) lower to midtroposphere, (b) upper troposphere, and (c) lower stratosphere. Also plotted is the ratio of RKE to DKE (thin black line). The reference line corresponds to the $-5 / 3$ slope. The legend for all panels is given in (a). 
HKE budget in the height coordinate system, suitable for the moist, fully compressible, nonhydrostatic atmosphere, is given by

$$
\begin{aligned}
\frac{\partial}{\partial t} E_{h}(\mathbf{k})= & t_{h}(\mathbf{k})+\partial_{z} F_{h \uparrow}(\mathbf{k})+\partial_{z} F_{p \uparrow}(\mathbf{k})+C_{A \rightarrow h}(\mathbf{k}) \\
& +\operatorname{Div}_{h}(\mathbf{k})+H_{h}(\mathbf{k})+J_{h}(\mathbf{k})+D_{h}(\mathbf{k}),
\end{aligned}
$$

where $(\partial / \partial t) E_{h}(\mathbf{k})$ is the total tendency term of HKE; $t_{h}(\mathbf{k})$ is the spectral transfer term of HKE due to nonlinear interactions; $F_{h \uparrow}(\mathbf{k})$ and $F_{p \uparrow}(\mathbf{k})$ are the vertical fluxes of HKE and pressure, respectively, thus $\partial_{z} F_{h \uparrow}(\mathbf{k})$ and $\partial_{z} F_{p \uparrow}(\mathbf{k})$ are corresponding vertical flux divergence terms; $C_{A \rightarrow h}(\mathbf{k})$ represents the spectral conversion of APE to HKE (herein the conversion term); $\operatorname{Div}_{h}(\mathbf{k})$ and $H_{h}(\mathbf{k})$ are the spectral tendencies due to 3D divergence and diabatic processes (herein the $3 \mathrm{D}$ divergence and diabatic terms), respectively; and $J_{h}(\mathbf{k})$ and $D_{h}(\mathbf{k})$ are the adiabatic nonconservative and diffusion terms, respectively. Detailed expressions for the above terms are given in the appendix, and the 1D spectra of these terms are constructed as for Eq. (3). Of these terms, $t_{h}$ is not a source/sink term but acts solely to redistribute energy across scales on a specific layer; $\partial_{z} F_{h \uparrow}, \partial_{z} F_{p \uparrow}$, and $H_{h}$ are all related to the moist processes, of which $\partial_{z} F_{h \uparrow}$ is associated with the vertical transportation of moist convection directly, $H_{h}$ is the direct forcing of diabatic effects, and $\partial_{z} F_{p \uparrow}$ corresponds to the vertical flux divergence of inertia-gravity wave (IGW) energy to some extent; the nonzero $\operatorname{Div}_{h}$ is due to the compressibility of the atmosphere; $D_{h}$ reflects the effect of diffusion.

The direction of the HKE cascade is always an attractive indicator of the formation mechanism of the atmospheric mesoscale $-5 / 3$ spectral slope, which can be evaluated based on the nonlinear spectral flux of HKE, defined as

$$
\Pi_{h}\left(k_{h}\right)=\int_{k_{h}}^{k_{h_{\max }}} t_{h}(k) d k,
$$

where $k_{h_{\max }}$ denotes the largest wavenumber. Note that the spectral flux defined here is exactly conservative; therefore, $\Pi_{h}(0)=\Pi_{h}\left(k_{h_{\max }}\right)=0$, and a positive (negative) nonlinear spectral flux denotes a downscale (upscale) HKE cascade.

In this section, we further divide the lower to midtroposphere $(z=0-5 \mathrm{~km})$ into the lower troposphere $(z=0-1.5 \mathrm{~km})$ and the midtroposphere $(z=2.5-5 \mathrm{~km})$ to provide a more detailed examination. Figure 8 shows the nonlinear spectral fluxes of HKE over different periods and heights, while the spectral HKE budget terms are presented in Figs. 9-11 .

\section{a. Slow intensification period}

During the SI period of the TC, the nonlinear spectral flux $\Pi_{h}$ (black lines in Fig. 8) is consistently positive in the lower troposphere (Fig. 8a), the upper troposphere (Fig. 8c), and the lower stratosphere (Fig. 8d), implying a continual downscale HKE cascade at these heights. In the midtroposphere (Fig. 8b), $\Pi_{h}$ is also predominantly positive yet has slightly negative values for $140<\lambda_{h}<200 \mathrm{~km}$, suggesting a weak upscale HKE cascade during this scale range and a downscale cascade for the remainder.

Figure 9 shows the spectral budget terms averaged over the SI period. In the context of leading a downscale HKE cascade, the overall cascade effect represented by the nonlinear transfer term $t_{h}$ is the loss (profit) of HKE at larger (smaller) scales, whereas the specific distribution varies over the vertical layers: in the lower troposphere (Fig. 9a), the $t_{h}$ term is negative for $\lambda_{h}>800 \mathrm{~km}$ and positive at smaller scales; in the midtroposphere (Fig. 9c), it is positive for $200<\lambda_{h}<600 \mathrm{~km}$ with a peak at $\lambda_{h}=500 \mathrm{~km}$, and negative at larger and smaller scales; in the upper troposphere and lower stratosphere (Figs. 9e,g), its effect is relatively weak.

The conversion term $C_{A \rightarrow h}$ represents the energy conversion between HKE and APE from buoyancy forcing. Its contribution is weak in the lower troposphere (Fig. 9a); in the mid- and upper troposphere (Figs. 9c,e), its contribution is mostly positive with a plateau for $\lambda_{h}>400 \mathrm{~km}$, suggesting a dominant conversion of APE to HKE; in the lower stratosphere (Fig. 9g), it crosses zero a few times but generally provides a negative contribution, which suggests that the buoyancy effect converts HKE to APE at this height.

After the outburst of moist convection in the TC, IGWs generated in the upper troposphere propagate upward and downward concurrently, resulting in upward pressure vertical flux $F_{p \uparrow}$ in the lower stratosphere and downward $F_{p \uparrow}$ throughout the troposphere (not shown). Consequently, the pressure flux divergence term $\partial_{z} F_{p \uparrow}$ during the SI period plays remarkable roles at various heights: it is entirely negative in the upper troposphere with a basin for $\lambda_{h}>400 \mathrm{~km}$ (Fig. 9e) and mostly positive for other layers (Figs. 9a,c,g), meaning that the HKE is carried away from the upper troposphere by IGWs and deposited into lower and higher layers.

Another important vertical flux term is the HKE vertical flux $F_{h \uparrow}$. The upward $F_{h \uparrow}$ (not shown) means that the moist convection transports the HKE vertically from the lower and midtroposphere to higher layers. Therefore, the HKE flux divergence term $\partial_{z} F_{h \uparrow}$ makes an overall negative contribution in the lower and midtroposphere with a valley at $\lambda_{h}=500 \mathrm{~km}$ (Figs. 9a,c), 

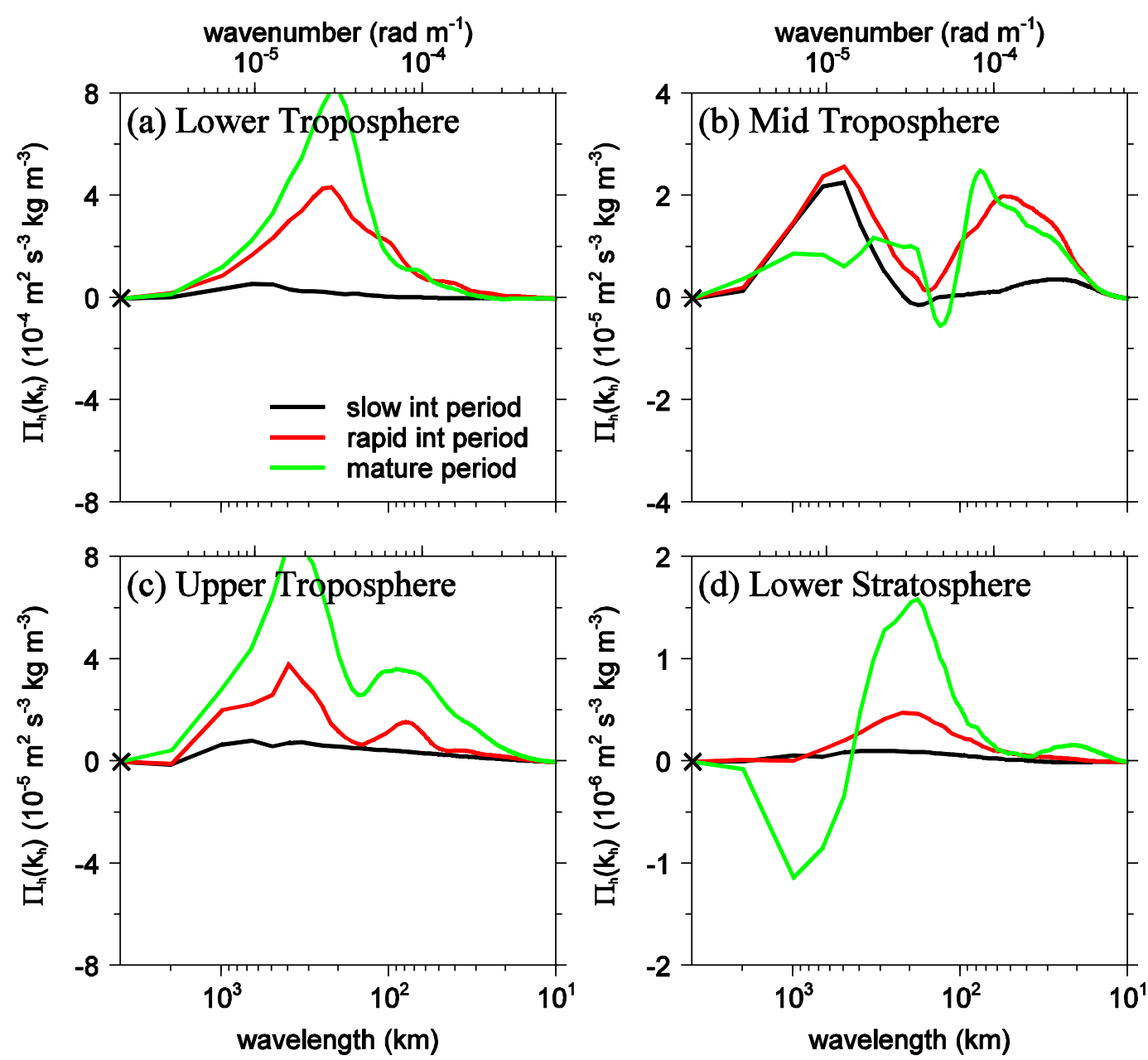

FIG. 8. Horizontal wavenumber spectra of the nonlinear spectral fluxes of HKE averaged in time over the SI period (black line), RI period (red line), and mature period (green line), and vertically over the (a) lower troposphere, (b) midtroposphere, (c) upper troposphere, and (d) lower stratosphere. The legend for all panels is given in (a). The value of any flux at the origin (denoted by $\times$ on the $y$ axis) has been modified so that it is equal to that of the corresponding flux at $k_{h}=0$.

and a positive contribution in the upper troposphere and lower stratosphere (Figs. 9e,g).

Irrespective of height, the 3D divergence term $\mathrm{Div}_{h}$ and the adiabatic nonconservative term $J_{h}$ have a consistent positive and negative contribution, respectively, notable in the mid- and upper troposphere (Figs. 9d,f). However, their combined net contribution in the midand upper troposphere is close to zero, indicating that the flow there is restricted by the anelastic approximation to a large extent (Peng et al. 2015b).

Because of the friction and turbulent dissipation, the diffusion term $D_{h}$ makes a significant negative contribution in the lower troposphere (Fig. 9b); for higher layers, it remains negative but with a tiny effect (Figs. 9d,f,h). In the mid- and upper troposphere (Figs. 9d,f), the diabatic term $H_{h}$ has a substantial negative contribution for $\lambda_{h}>400 \mathrm{~km}$, whereas in the lower troposphere and stratosphere (Figs. 9b,h), it is noticeably weak.

Interestingly, the majority of budget terms in the troposphere develop a local extreme at $\lambda_{h}=500 \mathrm{~km}$, suggesting that during this period the activity and development of energy concentrates on the cyclone scale, and energy at smaller scales is inactive. Consequently, the spectral peak of HKE at the cyclone scale forms gradually and holds until the mature period (refer to Figs. 3, 4, 6).

\section{b. Rapid intensification and mature period}

In the RI period of the TC, the nonlinear spectral flux $\Pi_{h}$ (red lines in Fig. 8) amplifies significantly. The weak negative fluxes in the midtroposphere disappear; thus, the HKE is governed by a steady downscale cascade from the lower troposphere to the lower stratosphere. 

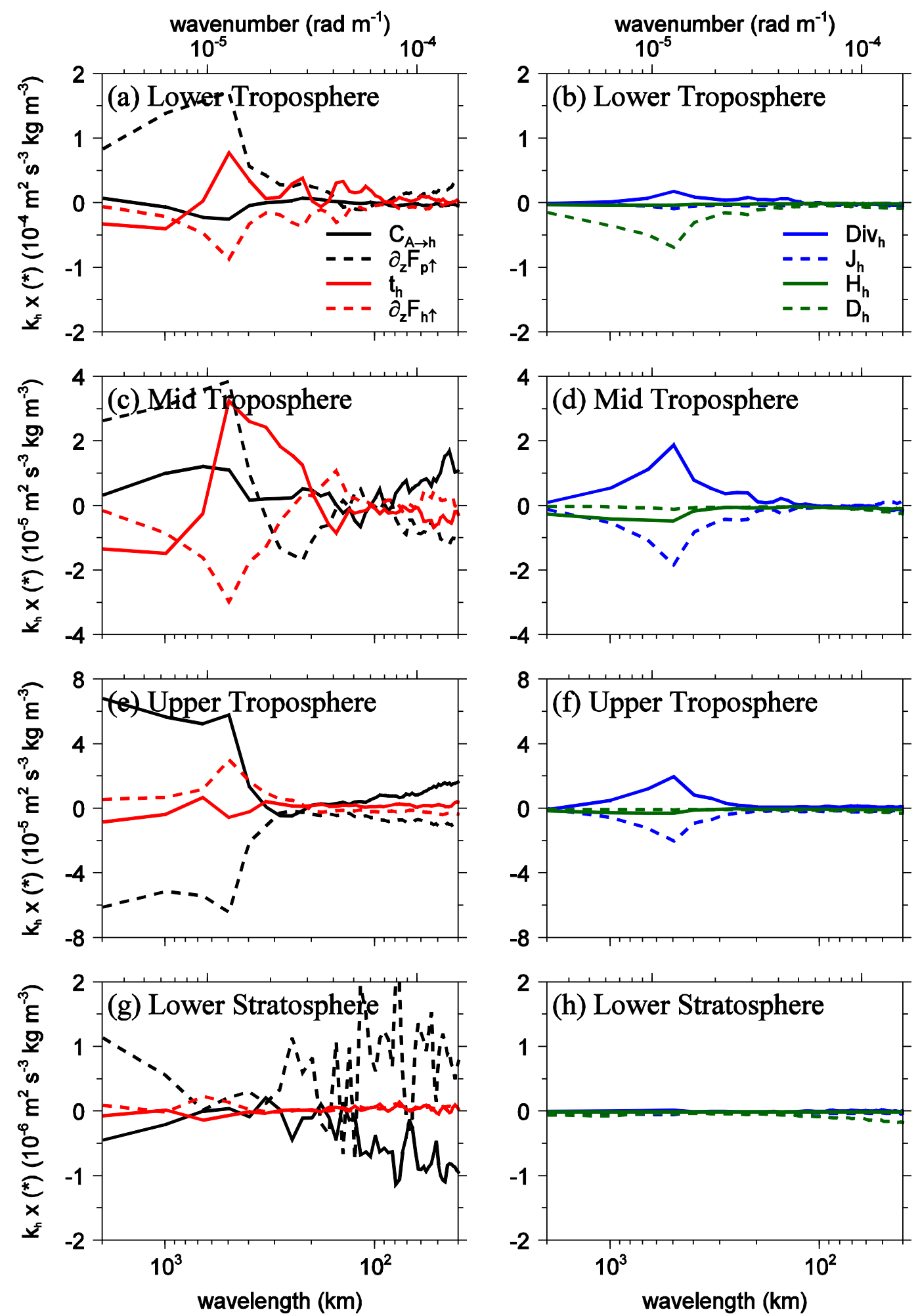

FIG. 9. Horizontal wavenumber spectra of the HKE budget terms averaged vertically over the (a),(b) lower troposphere, (c),(d) midtroposphere, (e),(f) upper troposphere, and (e),(f) lower stratosphere, and in time over the SI period. The legend for the left panels is given in (a) and that for the right panels in (b). The asterisk represents any one of the budget terms. The spectra are multiplied by $k_{h}$ to preserve area in log-linear coordinates. 

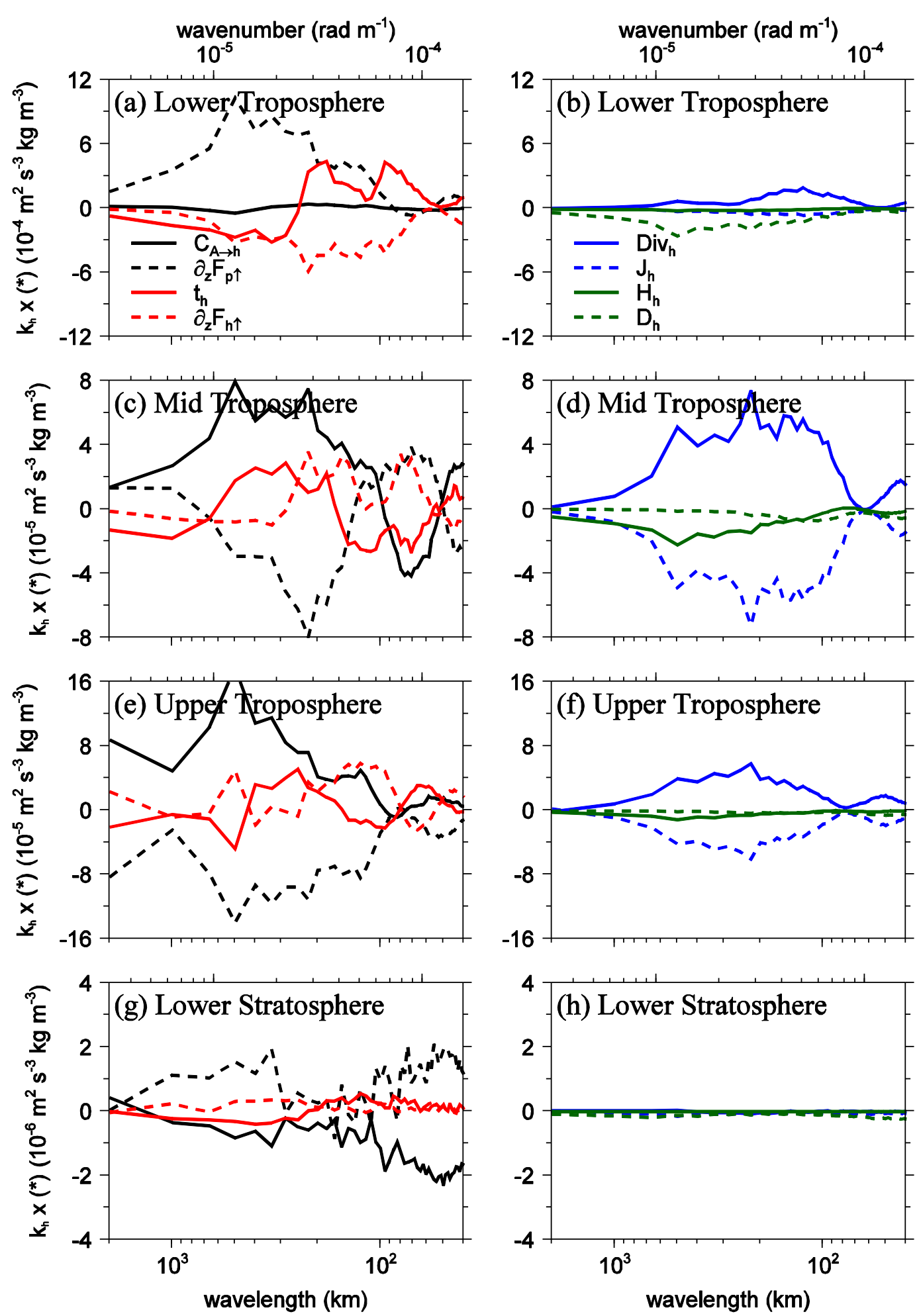

FIG. 10. As in Fig. 9, but averaged in time over the RI period. 

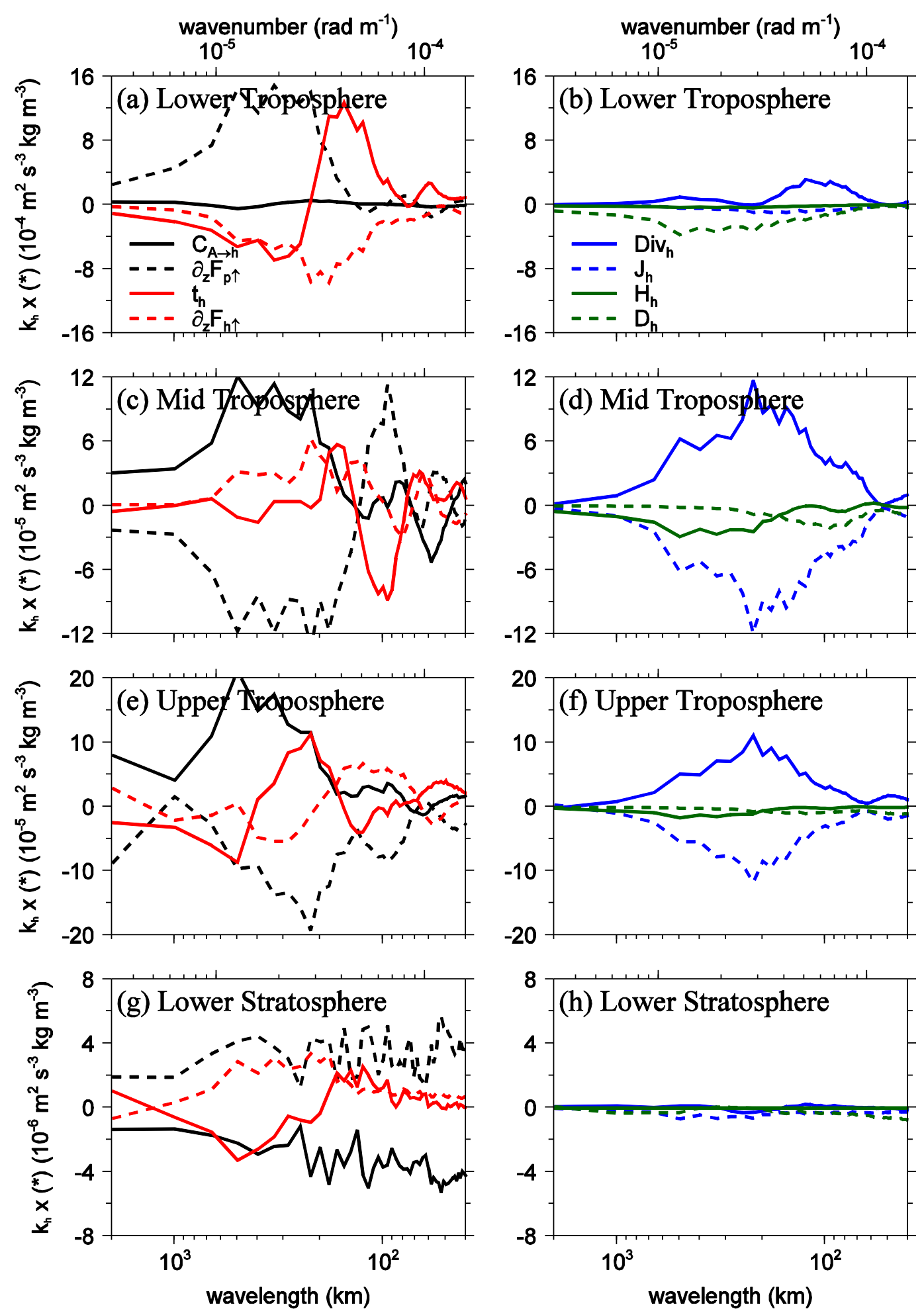

FIG. 11. As in Fig. 9, but averaged in time over the mature period. 
Compared with those during the SI period, all budget terms amplify during the RI period (Fig. 10). Extremes at the cyclone scale are no longer distinct, and contributions at smaller scales manifest. The nonlinear transfer term $t_{h}$ still exhibits a "negative to positive" distribution with wavenumber in the lower troposphere, but now crosses zero at $\lambda_{h}=250 \mathrm{~km}$ (Fig. 10a); a similar pattern is apparent in the lower stratosphere (Fig. 10g), with the zero crossing at $\lambda_{h}=200 \mathrm{~km}$. Its distribution is more complex and variable in the mid- and upper troposphere (Figs. 10c,e). The conversion term $C_{A \rightarrow h}$ continues to make prominent contributions from the midtroposphere to lower stratosphere. It develops a plateau for $200<\lambda_{h}<800 \mathrm{~km}$ in the midtroposphere (Fig. 10c) and a local peak at $\lambda_{h}=500 \mathrm{~km}$ in the upper troposphere (Fig. 10e).

The pressure flux divergence term $\partial_{z} F_{p \uparrow}$ and HKE flux divergence term $\partial_{z} F_{h \uparrow}$ are still important for all layers but differ from those during the SI period. The $\partial_{z} F_{p \uparrow}$ term in the midtroposphere contributes negatively for $150<\lambda_{h}<660 \mathrm{~km}$ (Fig. 10c), indicating that downward-propagating IGWs generate remarkably in the midtroposphere as well as in the upper troposphere. Local upward $F_{p \uparrow}$ appears in the lower and midtroposphere around $\lambda_{h}=80 \mathrm{~km}$, suggesting that upwardpropagating IGWs initiate at this scale from the lower troposphere, resulting in a positive contribution of $\partial_{z} F_{p \uparrow}$ for $50<\lambda_{h}<125 \mathrm{~km}$ in the midtroposphere (Fig. 10c). The moist convection continues to transport HKE from lower to upper layers, but $\partial_{z} F_{h \uparrow}$ in the midtroposphere switches from a sink to a source term for HKE, producing positive contributions for $60<\lambda_{h}<250 \mathrm{~km}$ (Fig. 10c).

The roles of the remaining terms- $\operatorname{Div}_{h}, J_{h}, D_{h}$, and $H_{h}$-are similar to those in the SI period, except for their distributions over broader scales (Figs. 10b,d,f,h).

Regarding the mature period, the amplitudes of the nonlinear spectral flux $\Pi_{h}$ (green lines in Fig. 8) and spectral budget terms (Fig. 11) further increase. Most of them exhibit similar distribution patterns as in the RI period, which should be because a complete TC system structure was already established during the RI period, whereas significant variations occur for $\Pi_{h}$ at some heights: in the midtroposphere (Fig. 8b), negative fluxes appear again for $110<\lambda_{h}<150 \mathrm{~km}$, meaning a weak local upscale HKE cascade; in the lower stratosphere (Fig. 8d), strongly negative fluxes develop over the large end of the mesoscale and intensive upscale cascade exists for $\lambda_{h}>400 \mathrm{~km}$.

\section{Summary and discussion}

In the present study, the evolution of an idealized TC is simulated using the ARW to investigate the mesoscale HKE spectra of the TC. During the SI period of the
$\mathrm{TC}$, the spectrum visibly grows over the central mesoscale in the troposphere and the large end of the mesoscale in the lower stratosphere. The spectral growth then saturates at larger scales and extends to smaller scales during the RI period. Finally, the spectra reach saturation and stability in the mature period. The saturated HKE spectra successfully reproduce the quasi $-5 / 3$ slope for $\lambda_{h}<500 \mathrm{~km}$; however, the specific spectral shapes vary between different heights. It exhibits a local peak at the cyclone scale and an arc-like shape at smaller scales in the troposphere, but a quasi-linear shape in the lower stratosphere.

Further examination of the RKE and DKE spectra suggests that the rotational mode dominates the divergent mode in the tropospheric mesoscale, reflecting the strong vorticity of the TC. However, the relative magnitude of DKE increases with height and the divergent mode dominates in the lower stratosphere, indicating the importance of IGW motion there.

A newly developed moist nonhydrostatic formulation of spectral HKE budget is employed to identify the physical processes behind the mesoscale HKE spectra. The results are depicted schematically in Fig. 12 and are summarized as follows:

1) Although a weak upscale HKE cascade exists at the narrow scale range around $\lambda_{h}=100 \mathrm{~km}$ in the midtroposphere during the SI and mature periods of the $\mathrm{TC}$, the HKE in the troposphere is generally dominated by a downscale cascade. In the lower stratosphere, the HKE is also governed by a downscale cascade during the SI and RI periods; however, an intensive upscale cascade occurs for $\lambda_{h}>400 \mathrm{~km}$ during the mature period.

2) The buoyancy effect plays a vital role from the midtroposphere to the lower stratosphere. In the midand upper troposphere, it converts APE to HKE, thus forming the most significant source of HKE, whereas in the lower stratosphere, it inversely converts HKE to APE, thus forming the most significant sink.

3) Two important vertical transportation processesthe propagation of IGWs and the transportation of moist convection-act to redistribute energy among various vertical layers. Accompanying the excitation and vertical propagation of IGWs, the HKE deposited by buoyancy forcing in the upper troposphere is efficiently transported by the waves to lower and higher layers. During the evolution of the TC, downwardpropagating and upward-propagating waves at certain scales are also evidently excited in the mid- and lower troposphere, respectively, resulting in local input and output of energy in the midtroposphere during the $\mathrm{RI}$ and mature periods. Conversely, the active moist 


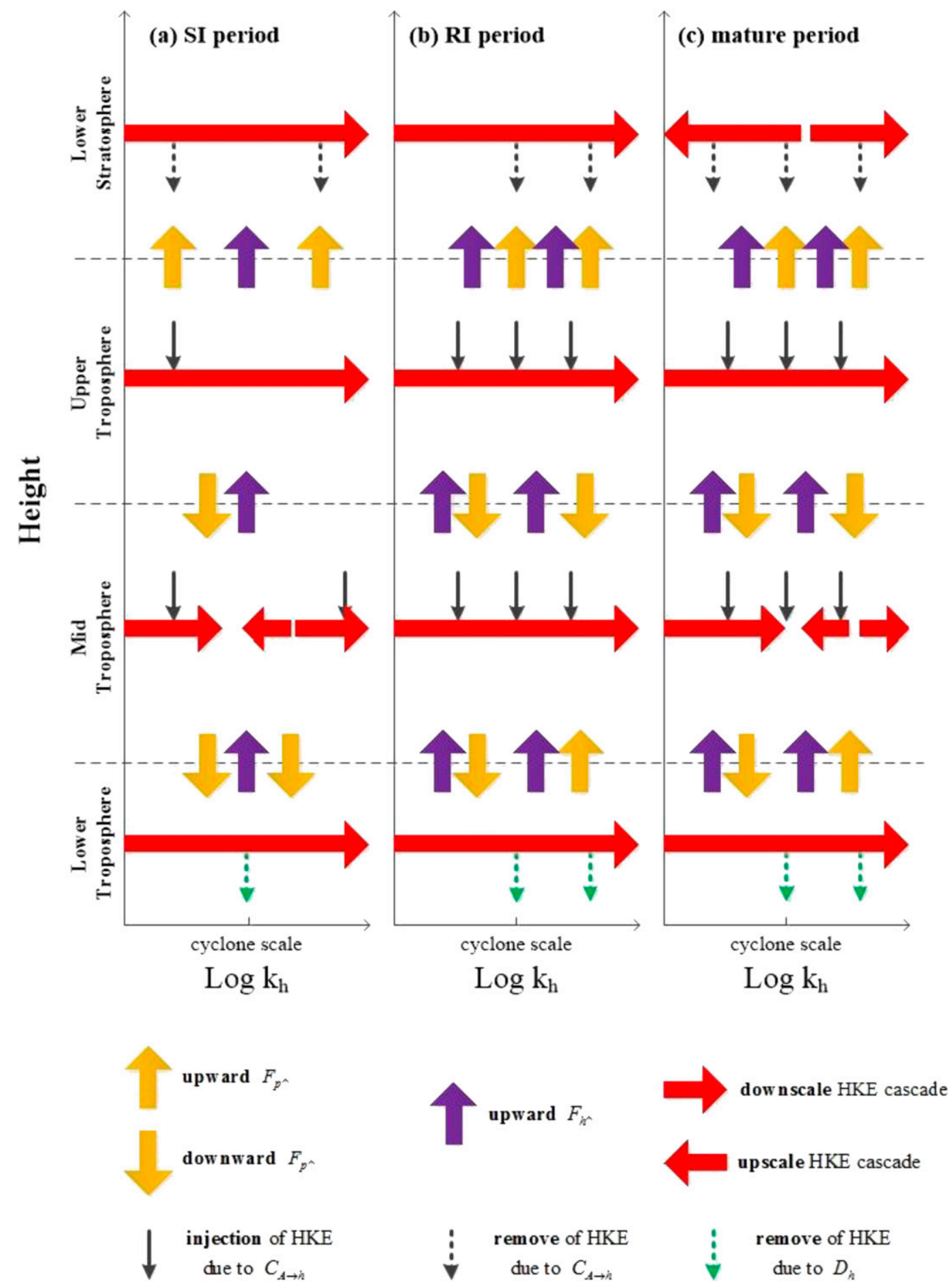

FIG. 12. Schematic of the HKE budgets vs horizontal wavenumber during the (a) SI, (b) RI, and (c) mature periods of the TC.

convection itself consistently transports the HKE upward from lower to higher layers.

4) The diffusion process continuously dissipates HKE, which is most evident in the lowest layers.
Theoretically, a downscale cascade means the nonlinear interactions transfer energy from larger to smaller scales. Therefore, the nonlinear transfer term should be positive (negative) at larger (smaller) scales, as was the 
case in the lower troposphere. However, the mid- and upper troposphere proves more complex: besides the negative values at the largest scales, the nonlinear term in these layers tends to develop a second negative area at much smaller scales. This suggests that for this area, it acts not only as a transition range during the dominant downscale transfer of energy, but also contributes to the smaller scales themselves. As the nonlinear interaction could not generate energy unaided, the energy necessarily comes from other physical processes. As shown in Figs. 9-11, the secondary negative areas of the nonlinear term consistently correspond to positive areas of the HKE flux divergence or pressure flux divergence term. Therefore, it is reasonable to deduce that the vertical transportation processes inject HKE into this local scale area, and the energy then tends to be cascaded to other scales through nonlinear interactions, which is significant toward the smaller scales. When the injection and cascade of energy is strong enough, it can even counteract the cascade from larger scales and result in a local upscale cascade, as seen in the midtroposphere.

From the perspective of atmospheric internal dynamics and energetics, the abundant moist processes in the TC are extremely crucial to the development of HKE spectra (and hence the TC) via their influence on various physical processes: as well as the direct vertical transportation of moist convection, IGW motion is also essentially excited by the convection; Y. Wang et al. (2018, unpublished manuscript) shows that APE-the key in buoyancy forcing-is generated by diabatic heating, which is mainly released by moist processes; and via HKE flux divergence and pressure flux divergence, the moist processes obviously modify the energy cascade process.

The formulation of spectral HKE budget used here is suitable for the internal atmosphere, but it has no function to identify the quantitative energy contribution from air-sea interaction to the TC. Therefore, we cannot directly evaluate the conditional instability of the second kind (CISK; Charney and Eliassen 1964; Ooyama 1964) mechanism or the wind-induced surface heat exchange (WISHE; Emanuel 1986; Rotunno and Emanuel 1987) mechanism, which are well-known theories proposed to explain the intensification and maintenance of TCs, and that emphasize the role of internal atmosphere and air-sea interaction, respectively. However, some insight can still be achieved. For example, although moist convection occurs early in our TC simulation, the energy activity is vibrant at the cyclone scale but is stagnant at the smaller convection scale during the SI period. During the RI period, however, the convection-scale energy activity becomes vigorous. In contrast, the mei-yu front system, which is strongly governed by the CISK mechanism, possesses abundant energy at the convection scale from the beginning of its development (Peng et al. 2014). Consequently, evident growth and uplift of the tropospheric HKE spectra in the TC initiate from larger scales and subsequently extend down to smaller scales, whereas the opposite occurs in the mei-yu front system. Different energy growth sequences among the scales result in considerably different spectral shapes, which is quasi linear in the mei-yu front. The unique energetics features of the TC indicate that the function of convection differs between the TC and mei-yu front system. Accordingly, the present results potentially favor the WISHE mechanism, which argues that rather than itself being the energy source, cumulus convection acts to rapidly transfer and redistribute the energy acquired from the ocean vertically through the troposphere.

Last, it is noteworthy that the cascade theories introduced in section 1 to explain the atmospheric mesoscale spectrum all share a common premise-that the atmospheric mesoscale can be idealized as a turbulent inertial subrange. In other words, the theories assume that energy is transferred to successively smaller or larger scales in a conservative manner with no significant source (or sink) of energy throughout the mesoscale (e.g., Waite and Snyder 2013), and that the energy cascade is the sole mechanism of atmospheric mesoscale spectrum formation. However, the mesoscale spectra in our TC simulation appear to represent the combined effect of the energy cascade, moist convection, IGW motion, and other processes. Based on the results of this study, it is inappropriate and insufficient to apply any proposed cascade theory alone to explain the formation of mesoscale spectra.

Acknowledgments. The authors wish to thank Dr. Chun-Chieh Wu and three anonymous reviewers for their helpful comments on the manuscript. This research is supported by the Beijige Open Research Fund for Nanjing Joint Center of Atmospheric Research Grant NJCAR2018ZD03, the National Nature Science Foundation for Young Scientists of China Grant 41705037, and the National Nature Science Foundation of China Grants 41775123 and 41375063.

\section{APPENDIX}

\section{Detailed Expressions of the Terms in the Spectral HKE Budget Equation}

Detailed mathematical expressions of the terms in Eq. (4) of section 4 are given as follows: 


$$
\begin{aligned}
t_{h}(\mathbf{k})= & \frac{1}{2}\left\{-\bar{\rho}_{d} \hat{\mathbf{u}}^{*} \cdot \operatorname{DFT}(\mathbf{u} \cdot \nabla \mathbf{u}+\mathbf{u} \nabla \cdot \mathbf{u} / 2)\right. \\
& +\bar{\rho}_{d}\left[\partial_{z} \hat{\mathbf{u}}^{*} \cdot \operatorname{DFT}(w \mathbf{u})\right. \\
& \left.\left.-\hat{\mathbf{u}}^{*} \cdot \operatorname{DFT}\left(w \partial_{z} \mathbf{u}\right)\right] / 2\right\}+ \text { c.c. }, \\
F_{h \uparrow}(\mathbf{k})= & -\frac{1}{4} \bar{\rho}_{d} \hat{\mathbf{u}}^{*} \cdot \operatorname{DFT}(w \mathbf{u})+\text { c.c. }, \\
F_{p \uparrow}(\mathbf{k})= & -\frac{1}{2} c_{p} \bar{\rho}_{d} \bar{\theta} \hat{w}^{*} \hat{\pi}^{\prime}+\text { c.c. }, \\
C_{A \rightarrow h}(\mathbf{k})= & \frac{1}{2} c_{p} \bar{\rho}_{d} \bar{\theta}^{*} \hat{w}^{*} \partial_{z} \hat{\pi}^{\prime}+\text { c.c. }, \\
\operatorname{Div}_{h}(\mathbf{k})= & \frac{1}{4} \bar{\rho}_{d} \hat{\mathbf{u}}^{*} \cdot \operatorname{DFT}\left[\mathbf{u}\left(\partial_{z} w+\nabla \cdot \mathbf{u}\right)\right]+\text { c.c. }, \\
H_{h}(\mathbf{k})= & \frac{1}{2} c_{p} \bar{\rho}_{d} \hat{H}_{m}^{*} \widehat{\pi}^{\prime}+\text { c.c. }, \\
J_{h}(\mathbf{k})= & -F_{h \uparrow}(\mathbf{k}) \partial_{z} \ln \bar{\rho}_{d},
\end{aligned}
$$

and

$$
D_{h}(\mathbf{k})=\frac{1}{2} \bar{\rho}_{d} \hat{\mathbf{u}}^{*} \cdot \hat{\mathcal{D}}_{\mathbf{u}}+\text { c.c. },
$$

where c.c. denotes the complex conjugate; $w$ is the vertical velocity; $\nabla$ is the horizontal gradient operator; $c_{p}$ is the specific heat of dry air at constant pressure; $\bar{\theta}$ is the potential temperature of dry reference state; $\pi^{\prime}=\pi-\bar{\pi}=$ $\left(p / p_{0}\right)^{R_{d} / c_{p}}-\left(\bar{p} / p_{0}\right)^{R_{d} / c_{p}}$ is the perturbed Exner pressure, with $p, p_{0}, \bar{p}$, and $R_{d}$ denoting pressure, reference surface pressure, dry reference-state pressure, and gas constant for dry air, respectively; $H_{m}=\left(1+1.61 q_{v}\right) S_{\theta}+1.61 \theta S_{q_{v}}$ represents the combined diabatic contributions, with $q_{v}$ denoting the water vapor mixing ratio, and $S_{\theta}$ and $S_{q_{v}}$ denote the diabatic contributions to $d \theta / d t$ and $d q_{v} / d t$, respectively; and $\mathcal{D}_{\mathbf{u}}$ represents the dissipation of $\mathbf{u}$.

\section{REFERENCES}

Bierdel, L., P. Friederichs, and S. Bentzien, 2012: Spatial kinetic energy spectra in the convection-permitting limited-area NWP model COSMO-DE. Meteor. Z., 21, 245-258, https:// doi.org/10.1127/0941-2948/2012/0319.

Charney, J. G., 1971: Geostrophic turbulence. J. Atmos. Sci., 28, 1087-1095, https://doi.org/10.1175/1520-0469(1971)028<1087: GT>2.0.CO;2.

—_ and A. Eliassen, 1964: On the growth of the hurricane depression. J. Atmos. Sci., 21, 68-75, https://doi.org/10.1175/ 1520-0469(1964)021<0068:OTGOTH >2.0.CO;2.

Dewan, E. M., 1979: Stratospheric wave spectra resembling turbulence. Science, 204, 832-835, https://doi.org/10.1126/ science.204.4395.832.

Dudhia, J., and Coauthors, 2008: Prediction of Atlantic tropical cyclones with the Advanced Hurricane WRF (AHW) model. 28th Conf. on Hurricanes and Tropical Meteorology, Orlando,
FL, Amer. Meteor. Soc., 18A.2, https://ams.confex.com/ams/ 28Hurricanes/webprogram/Paper138004.html.

Emanuel, K. A., 1986: An air-sea interaction theory for tropical cyclones. Part I: Steady-state maintenance. J. Atmos. Sci., 43, 585-605, https://doi.org/10.1175/1520-0469(1986)043<0585: AASITF $>2.0 . \mathrm{CO} ; 2$.

Gage, K. S., 1979: Evidence for a $k^{-5 / 3}$ law inertial range in mesoscale two-dimensional turbulence. J. Atmos. Sci., 36, 1950-1954, https://doi.org/10.1175/1520-0469(1979)036<1950: EFALIR $>2.0 . \mathrm{CO} ; 2$.

Hong, S.-Y., and J.-O. J. Lim, 2006: The WRF single-moment 6-class microphysics scheme (WSM6). J. Korean Meteor. Soc., 42, 129-151.

_- Y. Noh, and J. Dudhia, 2006: A new vertical diffusion package with an explicit treatment of entrainment processes. Mon. Wea. Rev., 134, 2318-2341, https://doi.org/10.1175/MWR3199.1.

Jordan, C. L., 1958: Mean soundings for the West Indies area. J. Meteor., 15, 91-97, https://doi.org/10.1175/1520-0469(1958) 015<0091:MSFTWI $>2.0 . \mathrm{CO} ; 2$.

Kim, S.-Y., and H.-Y. Chun, 2010: Stratospheric gravity waves generated by Typhoon Saomai (2006): Numerical modeling in a moving frame following the typhoon. J. Atmos. Sci., 67, 3617-3636, https://doi.org/10.1175/2010JAS3374.1.

Klemp, J. B., J. Dudhia, and A. D. Hassiotis, 2008: An upper gravity-wave absorbing layer for NWP applications. Mon. Wea. Rev., 136, 3987-4004, https://doi.org/10.1175/ 2008MWR2596.1.

Koshyk, J. N., and K. Hamilton, 2001: The horizontal kinetic energy spectrum and spectral budget simulated by a highresolution troposphere-stratosphere-mesosphere GCM. J. Atmos. Sci., 58, 329-348, https://doi.org/10.1175/1520-0469(2001) 058<0329:THKESA $>2.0$. CO;2.

Kuester, M. A., M. J. Alexander, and E. A. Ray, 2008: A model study of gravity waves over Hurricane Humberto (2001). J. Atmos. Sci., 65, 3231-3246, https://doi.org/10.1175/2008JAS2372.1.

Lindborg, E., 2006: The energy cascade in a strongly stratified fluid. J. Fluid Mech., 550, 207-242, https://doi.org/10.1017/ S0022112005008128.

— tions in the upper troposphere and lower stratosphere. 2. Theoretical considerations. J. Geophys. Res., 106, $10233-$ 10 241, https://doi.org/10.1029/2000JD900815.

Lorenz, E. N., 1969: The predictability of a flow which possesses many scales of motion. Tellus, 21, 289-307, https://doi.org/ 10.1111/j.2153-3490.1969.tb00444.x.

Marks, F. D., Jr., and L. K. Shay, 1998: Landfalling tropical cyclones: Forecast problems and associated research opportunities. Bull. Amer. Meteor. Soc., 79, 305-323.

Nastrom, G. D., and K. S. Gage, 1985: A climatology of atmospheric wavenumber spectra observed by commercial aircraft. J. Atmos. Sci., 42, 950-960, https://doi.org/10.1175/15200469(1985)042<0950:ACOAWS > 2.0.CO;2.

Ooyama, K., 1964: A dynamical model for the study of tropical cyclone development. Geofys. Int., 4, 187-198.

Peng, J., L. Zhang, Y. Luo, and Y. Zhang, 2014: Mesoscale energy spectra of the mei-yu front system. Part I: Kinetic energy spectra. J. Atmos. Sci., 71, 37-55, https://doi.org/10.1175/ JAS-D-13-085.1.

_ - _ and J. Guan, 2015a: Applications of a moist nonhydrostatic formulation of the spectral energy budget to baroclinic waves. Part I: The lower-stratospheric energy spectra. J. Atmos. Sci., 72, 2090-2108, https://doi.org/10.1175/JAS-D-140306.1. 
and $-2015 \mathrm{~b}$ : Applications of a moist nonhydrostatic formulation of the spectral energy budget to baroclinic waves. Part II: The upper-tropospheric energy spectra. J. Atmos. Sci., 72, 3923-3939, https://doi.org/10.1175/JAS-D-14-0359.1.

Riley, J. J., and S. M. deBruynKops, 2003: Dynamics of turbulence strongly influenced by buoyancy. Phys. Fluids, 15, 2047-2059, https://doi.org/10.1063/1.1578077.

Ritchie, E. A., and G. J. Holland, 1997: Scale interactions during the formation of Typhoon Irving. Mon. Wea. Rev., 125, 1377-1396, https://doi.org/10.1175/1520-0493(1997)125<1377: SIDTFO $>2.0 . C O ; 2$.

Rogers, R. F., P. D. Reasor, and J. A. Zhang, 2015: Multiscale structure and evolution of Hurricane Earl (2010) during rapid intensification. Mon. Wea. Rev., 143, 536-562, https://doi.org/ 10.1175/MWR-D-14-00175.1.

Rotunno, R., and K. A. Emanuel, 1987: An air-sea interaction theory for tropical cyclones. Part II: Evolutionary study using a nonhydrostatic axisymmetric numerical model. J. Atmos. Sci., 44, 542-561, https://doi.org/10.1175/15200469(1987)044<0542:AAITFT>2.0.CO;2.

— the predictability of flows with many scales of motion. J. Atmos. Sci., 65, 1063-1076, https://doi.org/10.1175/2007JAS2449.1.

Skamarock, W. C., 2004: Evaluating mesoscale NWP models using kinetic energy spectra. Mon. Wea. Rev., 132, 3019-3032, https://doi.org/10.1175/MWR2830.1.

, and Coauthors, 2008: A description of the Advanced Research WRF Version 3. NCAR Tech. Note NCAR/ TN-475+STR, 113 pp., http://dx.doi.org/10.5065/D68S4MVH.
Sun, Y. Q., and F. Zhang, 2016: Intrinsic versus practical limits of atmospheric predictability and the significance of the butterfly effect. J. Atmos. Sci., 73, 1419-1438, https://doi.org/10.1175/ JAS-D-15-0142.1.

_ , R. Rotunno, and F. Zhang, 2017: Contributions of moist convection and internal gravity waves to building the atmospheric $-5 / 3$ kinetic energy spectra. J. Atmos. Sci., $\mathbf{7 4}$ 185-201, https://doi.org/10.1175/JAS-D-16-0097.1.

Tulloch, R., and K. S. Smith, 2006: A theory for the atmospheric energy spectrum: Depth-limited temperature anomalies at the tropopause. Proc. Natl. Acad. Sci. USA, 103, 14 690-14 694, https://doi.org/10.1073/pnas.0605494103.

Tung, K. K., and W. W. Orlando, 2003: The $k^{-3}$ and $k^{-5 / 3}$ energy spectrum of atmospheric turbulence: Quasigeostrophic two-level model simulation. J. Atmos. Sci., 60, 824-835, https://doi.org/10.1175/1520-0469(2003)060<0824: TKAKES $>2.0 . \mathrm{CO} ; 2$

Vonich, P. T., and G. J. Hakim, 2018: Hurricane kinetic energy spectra from in situ aircraft observations. J. Atmos. Sci., 75, 2523-2532, https://doi.org/10.1175/JAS-D-17-0270.1.

Waite, M. L., and P. Bartello, 2004: Stratified turbulence dominated by vortical motion. J. Fluid Mech., 517, 281-308, https:// doi.org/10.1017/S0022112004000977.

_ and C. Snyder, 2009: The mesoscale kinetic energy spectrum of a baroclinic life cycle. J. Atmos. Sci., 66, 883-901, https:// doi.org/10.1175/2008JAS2829.1.

_ and - 2013: Mesoscale energy spectra of moist baroclinic waves. J. Atmos. Sci., 70, 1242-1256, https://doi.org/10.1175/ JAS-D-11-0347.1. 